\title{
Postero-Lateral Fusion (PLF) for Degenerative Diseases of the Lumbosacral Spine in Jos Nigeria
}

\author{
Ode Michael Bundepuun ${ }^{1}$, Taiwo Femi Olu ${ }^{1}$, Onche Icha Inalegwu ${ }^{1}$, Amupitan Idumagbodi, \\ Ode Gloria Nengi ${ }^{2}$
}

${ }^{1}$ Department of Orthopaedics and Trauma, Jos University Teaching Hospital, Jos, Nigeria

${ }^{2}$ Department of Community Medicine, Jos University Teaching Hospital, Jos, Nigeria

\section{Email address:}

odemb2014@gmail.com (O. M. Bundepuun)

${ }^{*}$ Corresponding author

\section{To cite this article:}

Ode Michael Bundepuun, Taiwo Femi Olu, Onche Icha Inalegwu, Amupitan Idumagbodi, Ode Gloria Nengi. Postero-Lateral Fusion (PLF) for Degenerative Diseases of the Lumbosacral Spine in Jos Nigeria. Journal of Surgery. Vol. 6, No. 4, 2018, pp. 97-100.

doi: $10.11648 /$ j.js.20180604.14

Received: June 7, 2018; Accepted: June 27, 2018; Published: July 21, 2018

\begin{abstract}
Degenerative diseases of the spine are a common presentation to the clinician, more so with an increase in the ageing population worldwide. Operative methods of treatment are employed following failure of conservative methods. Spine surgical procedures are expensive, and many different procedures are employed to treat these spinal conditions. Instrumented posterolateral fusion (PLF) is one of the options employed and has a reduced cost owing to the absence of the inter body cage used in inter body fusion techniques. The objective of this study was to assess posterolateral fusions in our center within a developing country with poor health insurance coverage as an effective treatment modality in degenerative lumbosacral spine disease, without the added cost of an interbody fusion cage. This was a retrospective study carried out in Jos, Nigeria covering a two year period from July 2015 to June 2017. Patients with degenerative spine diseases who had been on conservative methods of treatment for more than six months with no significant improvement were recruited for the study. Data was obtained from the case records of the patients the patients were assessed for the indications for the procedure, the number of levels of fusion, duration of surgery and transfusion requirement as well as outcome of procedure using the Numeric pain scale (11 point scale from 0 to 10) and the complications of the procedure. Data was analyzed using the epi info statistical software. 13 patients had Posterolateral fusion (PLF) within this period. The mean age was 61.4years \pm 10.7 . A male female ratio of M:F 1:3.3. 8(61.5\%) patients had multiple level disc degeneration and herniation, $2(15.4 \%)$ patients each had spinal canal stenosis and facet joint arthritis with instability and 1(7.7\%) had degenerative spondylolisthesis. 9(69.2\%) patients had 2 level fusion, 2 (15.4\%) had 3 level fusion and 2(15.4\%) had 1 level fusion. 6(46.2\%) had a pain reduction by $\geq 8$ points on the numeric pain scale, $6(46.2 \%)$ had reduction by 6-7 points and $1(7.7 \%)$ had reduction of 3-5 points. $92.6 \%$ of the patients had a pain reduction by more than $50 \%$. Mean operative time was 203 minutes, and mean transfusion requirement was 2.8 pints of blood. Complications noted were superficial surgical site infection 1 patient and dural tear 1 patient. Postero lateral fusion techniques are a safe and effective treatment modality in treating patients with degenerative lumbosacral spine disease. The non usage of the interbody fusion cage provides a cheaper alternative in posterolateral fusion and every modality to limit surgical site infection should be employed to limit increased cost from this complication.
\end{abstract}

Keywords: Posterolateral, Fusion, Degenerative, Lumbosacral, Spine, Jos, Nigeria

\section{Introduction}

Degenerative diseases of the spine are a group of spinal conditions that typically occur with advancing age. The range of these conditions include; facet joint arthritis, spinal canal stenosis, spondylolisthesis, disc degeneration and herniation and hypertrophy of the ligamentum flavum. [1] These conditions may be associated with instability of the 
lumbosacral spine that may result in lumbosacral scoliosis. The effect of these conditions is that there is a compression of the neural structures resulting in radiculopathies as well as impaired functionality of structures supplied by these nerves. There may be an associated mechanical back pain. These diseases commonly occur with advancing age even though some of these conditions are present in young individuals. With improvement in health care globally and even in the developing world, clinicians are now being confronted with such older patients in an ever increasing manner. [1-3]

These conditions are treated by non operative and operative modalities. Operative modalities are employed following the failure of non operative treatments. There is a wide range of operative treatment modalities employed and the choice for which method is employed depends on; the pathology to be treated, the available facilities, the experience and competence of the surgical team as well as the cost of the procedure. These operative techniques could be open or minimally invasive surgical procedures among which include; laminectomies (total or hemi laminectomies), discectomies (these may be accompanied by fusions of the spinal levels, particularly where instability exists or the surgical decompression may result in spinal instability). Fusion techniques may be non instrumented using only bone graft with/without bone graft substitutes or they may be instrumented employing pedicle screws, rods and cages with bone grafts to achieve fusion. [4-6]. Some of these instrumented techniques of fusion are; instrumented posterolateral fusion (PLF), anterolateral inter body fusion (ALIF), posterior inter body fusion (PLIF), Transforaminal inter body fusion (TLIF). [7-10] Asides the posterolateral fusion, the other techniques employ the use of interbody cages for interbody fusions. Instrumented Posterolateral fusions (PLF) can be done alone as a procedure and has been shown to be effective in treating such conditions or can be combined with the various types of interbody fusion techniques. [10-13].

Spine procedures can be quite expensive. [14], and in a developing country like Nigeria, rated as a low/middle income country with a large proportion of her citizens living below the poverty line. [15] coupled with a very limited medical insurance system, the financial burden on these patients who mostly make out of pocket payment for medical services can be reduced by limiting the overall cost of treatment. Thus in eliminating the use of the interbody fusion procedures with a cage which is expensive [16], the overall cost of the procedure is eventually lessened. The objective of the study was to assess the outcome of the instrumented posterolateral fusion technique in our setting.

\section{Methodology}

This was a retrospective study carried out in Jos, Nigeria covering a two year period from July 2015 to June 2017. Patients with degenerative spine diseases who had been on conservative methods of treatment for more than six months with no significant improvement were recruited for the study. The diagnosis of degenerative spine disease was made from clinical evaluation and magnetic resonance imaging findings.
Data was obtained from the case records of the patients. The patients who had instrumented posterolateral fusion (PLF) were included and those who had other surgical treatment techniques other than instrumented postero lateral fusion were excluded from the study. The patients had instrumented posterolateral fusion, which involved a posterior approach to the lumbosacral spine and a laminectomy with the placement of pedicle screws at the involved levels with bone graft and bone graft substitute (Hydroxyapatite) placed along the pre decorticated beds of the transverse processes. The patients were assessed for the indication for the procedure, the number of levels of fusion, duration of surgery and transfusion requirement as well as outcome of procedure using the Numeric pain scale (11 point scale from 0 to 10 ). $[17,18]$ and the complications of the procedure.. Data was analysed using the epi info statistical software.

\section{Results}

13 patients had Posterolateral fusion (PLF) within this period. The ages of the patients ranged from 35 to 72 years with a mean age of 61.4 years \pm 10.7 . There was a male female ratio of M: F 1:3.3.8(61.5\%) patients had multiple level disc degeneration and herniation, 2(15.4\%) patients each had spinal canal stenosis and facet joint arthritis with instability and $1(7.7 \%)$ had degenerative spodylolisthesis. Table 19 (69.2\%) patients had 2 level fusion, 2 (15.4\%) had 1 level fusion and $2(15.4 \%)$ had 3 level fusion. Table 2 $6(46.2 \%)$ had very good outcomes (pain reduction $\geq 8$ points), $6(46.2 \%)$ had good outcomes pain reduction (6-7 points reduction) and $1(7.7 \%)$ had a fair outcome. (3-5 point reduction) Table $392.6 \%$ of the patients had a pain scale reduction by more than $50 \%$. Mean operative time was 203 minutes, and mean transfusion requirement was 2.8 pints of blood. Complications noted were superficial surgical site infection 1 patient and dural tear 1 patient.

Table 1. Pathologies treated.

\begin{tabular}{lll}
\hline Diagnosis & Number & Percentage \\
\hline Disc degeneration and herniation & 8 & $61.5 \%$ \\
Spinal canal stenosis & 2 & $15.4 \%$ \\
Facet joint arthritis with instability & 2 & $15.4 \%$ \\
Degenerative spondylolisthesis & 1 & $7.7 \%$ \\
Total & 13 & $100 \%$ \\
\hline
\end{tabular}

Table 2. Fusion levels.

\begin{tabular}{lll}
\hline Levels & Number & Percentage \\
\hline One level fusion & 2 & $15.4 \%$ \\
Two level fusion & 9 & $69.2 \%$ \\
Three level fusion & 2 & $15.4 \%$ \\
Total & 13 & $100 \%$ \\
\hline
\end{tabular}

Table 3. Outcome (Numeric pain scale assessment).

\begin{tabular}{lll}
\hline Reduction on pain scale & Number & percentage \\
\hline$\geq 8$ point reduction & 6 & $46.2 \%$ \\
6-7 point reduction & 6 & $46.2 \%$ \\
$3-5$ point reduction & 1 & $7.7 \%$ \\
Total & 13 & $100 \%$ \\
\hline
\end{tabular}




\section{Discussion}

In our study, the mean age for the posterolateral fusion procedure was 61.4 years. This age is not to different from that obtained by Mina. C and colleagues who found a mean age of 59years in their study [19]. In the study by David Reginald et al on degenerative spondylolisthesis they found an average age of 63years [20]. These conditions are degenerative and thus it is expected that the patients will fall within this age range. With the global increase in the ageing population attributed to ever improving health care, it is believed that more of such patients will be encountered. In Nigeria where spine surgery is now being more sought after, due to growing awareness of the availability of such procedures within the country it is believed that an even greater number of patients would present for such services to gain some improvement in their quality of life with the background of limited financial resources. The commonest degenerative condition that we encountered in our study was multiple disc degeneration with herniation in $61.5 \%$ of patients, with degenerative spondylolisthesis being the least encountered $(7.7 \%)$. However in the study carried out by Xiao $\mathrm{R}$ et al degenerative spondylolisthesis was the commonest condition found in $56.2 \%$ of those who had mostly posterolateral fusion [21] We carried out mostly two level fusions in $69.2 \%$ of the procedures, while the others were one level and three level fusions both $15.4 \%$ each

$46.2 \%$ of the patients had pain reduction of 8 or more points on the pain scale, while another $46.2 \%$ had a pain scale reduction of between 6 to 7 points. This represents a marked reduction on the pain post operatively with a good degree of patient satisfaction following the procedure. The pain experienced is one of the worst symptoms from degenerative spine diseases. In the study by Omidi-Kashani and colleagues they found a significant reduction in pain scores in patients who underwent posterolateral fusion for degenerative spondylolisthesis. [12]. Zhou Z. J. et al found posrterolateral fusion an effective method in reducing the pain from degenerative lumbosacral spine diseases in their study [22]. Robinson $\mathrm{Y}$ et al also found a reduction in pain for degenerative disc disease following posterolateral fusion. [4]. $92.4 \%$ of our patients had a pain scale reduction by $50 \%$ or more. We assessed pain as it is one of the most worrisome symptoms of degenerative spine disease and it significantly affects the quality of life of affected patients and the chronic nature of such pain can sometines lead to psychological illnesses such as depression. The above findings attest to the effectiveness of instrumented posterolateral fusion without an interbody fusion cage in the treatment of such degenerative conditions of the lumbosacral spine and resulting in appreciable pain relief. Our findings encourage us to employ this method of treatment particularly in our setting were financial considerations are a major part of decision making in arriving at the most appropriate method of care, particularly in patients who have limited financial means.

One of our patients had superficial surgical site infection which was treated by daily wound dressings and antibiotics following culture results and the wound healed subsequently. Another patient had a dural tear with cerebro spinal fluid leak which was noticed post operatively. This was managed conservatively and the drainage stopped by the $8^{\text {th }}$ postoperative day. De la Graza-Ramos $\mathrm{R}$ et al in their study found an overall surgical site infection rate of $0.72 \%$, and specific to posterolateral fusion, an infection rate of $1.04 \%$.[23]. In the study by Chotai $S$ etal [24] the most frequent complication following lumbar spine surgery was surgical site infection with superficial surgical site infection being more frequent. Shimuzu et al in their study had surgical site infection as one of their leading complications with others being; postoperative epidural haematoma and pedicle screw malpositioning. [25]. Post operative surgical site infection appears from the revealed literature a common complication and this was also encountered in our study. This complication can be a superficial surgical site infection or more gravely a deep surgical site infection which may require surgical debridement or other procedures to treat. This can result in increased cost of care. For our patients in whom cost of care is a severely limiting factor in determing those who have such procedures, everything must be done e.g strict asepsis and antibiotic prophylaxis, to avoid such a complication that can dramatically increase the cost of care. Ojo et al in their study of surgical site infection in posterior spine surgeries,[26] advocate early postoperative wound dressings, frequent dressings and non touch technique in dressings change as well as good control of co morbidities such as diabetes mellitus, as a means of reducing the occurrence of surgical site infections in such patients.

We had a mean operation time of 203 minute for this procedure. The three level fusion procudures taking a longer period. The mean transfusion requirement was 2.8 litres. Thus we advocate at least three units of blood available for such procedures.

In our study we had a limited number of patients due largely to the inability of many patients deserving surgery being able to afford to pay for surgery. This, coupled with the poor health insurance coverage for such procedures, limited our study only those who could make out of pocket payments for the procedure.

\section{Conclusion}

Postero lateral fusion techniques are a safe and effective treatment modality in treating patients with degenerative lumbosacral spine disease. The non usage of the interbody fusion cages makes them a cheaper alternative to interbody fusion tecniques which employ cages. In developing country like Nigeria with poor insurance coverage and out of pocket payments made for health care by a largely poor population, a reduction in cost for spine surgery procedures which are nevertheless expensive surgical procedures will help to grant such procedures to greater number of patients.

Every possible modality should be employed in limiting the occurrence of surgical site infection which can lead to an increased cost of care. 


\section{References}

[1] Ong KL, Auerbach JD, Lau E, Schmier J, Ochoa JA. Perioperative outcomes, complications, and costs associated with lumbar spinal fusion in older patients with spinal stenosis and spondylolisthesis. Neurosurgical focus. 2014; 36 (6):E5.

[2] Kobayashi K, Ando K, Nishida Y, Ishiguro N, Imagama S. Epidemiological trends in spine surgery over 10 years in a multicenter database. European spine journal: official publication of the European Spine Society, the European Spinal Deformity Society, and the European Section of the Cervical Spine Research Society. 2018.

[3] Norton RP, Bianco K, Klifto C, Errico TJ, Bendo JA. Degenerative Spondylolisthesis: An Analysis of the Nationwide Inpatient Sample Database. Spine. 2015; 40 (15):1219-27.

[4] Robinson Y, Michaelsson K, Sanden B. Instrumentation in lumbar fusion improves back pain but not quality of life 2 years after surgery. A study of 1,310 patients with degenerative disc disease from the Swedish Spine Register SWESPINE. Acta orthopaedica. 2013; 84 (1): 7-11.

[5] Pannell WC, Savin DD, Scott TP, Wang JC, Daubs MD. Trends in the surgical treatment of lumbar spine disease in the United States. The spine journal: official journal of the North American Spine Society. 2015; 15 (8): 1719-27.

[6] Campbell RC, Mobbs RJ, Lu VM, Xu J, Rao PJ, Phan K. Posterolateral Fusion Versus Interbody Fusion for Degenerative Spondylolisthesis: Systematic Review and Meta-Analysis. Global spine journal. 2017; 7 (5): 482-90.

[7] Lubelski D, Alentado VJ, Williams SK, O'Rourke C, Obuchowski NA, Wang JC, et al. Variability in Surgical Treatment of Spondylolisthesis Among Spine Surgeons. World neurosurgery. 2018; 111: e564-e72.

[8] Lubelski D, Williams SK, O'Rourke C, Obuchowski NA, Wang JC, Steinmetz MP, et al. Differences in the Surgical Treatment of Lower Back Pain Among Spine Surgeons in the United States. Spine. 2016; 41 (11):978-86.

[9] Yoshihara H, Yoneoka D. National trends in the surgical treatment for lumbar degenerative disc disease: United States, 2000 to 2009 . The spine journal: official journal of the North American Spine Society. 2015; 15 (2):265-71.

[10] Macki M, Bydo M, Weingart R, Sciubba D, Wolinsky JP, Gokaslan ZL, et al. Posterolateral fusion with interbody for lumbar spondylolisthesis is associated with less repeat surgery than posterolateral fusion alone. Clinical neurology and neurosurgery. 2015 ; 138: 117-23.

[11] McAnany SJ, Baird EO, Qureshi SA, Hecht AC, Heller JG, Anderson PA. Posterolateral Fusion Versus Interbody Fusion for Degenerative Spondylolisthesis: A Systematic Review and Meta-Analysis. Spine. 2016; 41 (23): E1408-E14.

[12] Omidi-Kashani F, Hasankhani EG, Rahimi MD, Khanzadeh R. Comparison of functional outcomes following surgical decompression and posterolateral instrumented fusion in single level low grade lumbar degenerative versus isthmic spondylolisthesis. Clinics in orthopedic surgery. 2014; 6 (2): 185-9.

[13] Noorian S, Sorensen K, Cho W. A systematic review of clinical outcomes in surgical treatment of adult isthmic spondylolisthesis. The spine journal: official journal of the North American Spine Society. 2018.

[14] Goz V, Rane A, Abtahi AM, Lawrence BD, Brodke DS, Spiker WR. Geographic variations in the cost of spine surgery. Spine. 2015; 40 (17): 1380-9.

[15] Doherty J, Kirigia D, Okoli C, Chuma J, Ezumah N, Ichoku $\mathrm{H}$, et al. Does expanding fiscal space lead to improved funding of the health sector in developing countries?: lessons from Kenya, Lagos State (Nigeria) and South Africa. Global health action. 2018; 11 (1): 1461338.

[16] Gottschalk MB, Premkumar A, Sweeney K, Boden SD, Heller J, Yoon ST, et al. Posterolateral Lumbar Arthrodesis With and Without Interbody Arthrodesis for L4-L5 Degenerative Spondylolisthesis: A Comparative Value Analysis. Spine. 2015; 40 (12): 917-25.

[17] Carreon LY, Glassman SD, Kantamneni NR, Mugavin MO, Djurasovic M. Clinical outcomes after posterolateral lumbar fusion in workers' compensation patients: a case-control study. Spine. 2010; 35 (19): 1812-7.

[18] Chan AK, Bisson EF, Bydon M, Glassman SD, Foley KT, Potts EA, et al. Women fare best following surgery for degenerative lumbar spondylolisthesis: a comparison of the most and least satisfied patients utilizing data from the Quality Outcomes Database. Neurosurgical focus. 2018; 44 (1): E3.

[19] Mina C, Carreon LY, Glassman SD. Impact of Lumbar Fusion on Health Care Resource Utilization. Spine. 2016; 41 (4):353-7.

[20] Davis R, Auerbach JD, Bae H, Errico TJ. Can low-grade spondylolisthesis be effectively treated by either coflex interlaminar stabilization or laminectomy and posterior spinal fusion? Two-year clinical and radiographic results from the randomized, prospective, multicenter US investigational device exemption trial: clinical article. Journal of neurosurgery Spine. 2013; 19 (2):174-84.

[21] Xiao R, Miller JA, Sabharwal NC, Lubelski D, Alentado VJ, Healy AT, et al. Clinical outcomes following spinal fusion using an intraoperative computed tomographic 3D imaging system. Journal of neurosurgery Spine. 2017; 26 (5):628-37.

[22] Zhou ZJ, Zhao FD, Fang XQ, Zhao X, Fan SW. Meta-analysis of instrumented posterior interbody fusion versus instrumented posterolateral fusion in the lumbar spine. Journal of neurosurgery Spine. 2011; 15 (3):295-310.

[23] De la Garza-Ramos R, Abt NB, Kerezoudis P, McCutcheon BA, Bydon A, Gokaslan Z, et al. Deep-wound and organ-space infection after surgery for degenerative spine disease: an analysis from 2006 to 2012. Neurological research. 2016; 38 (2):117-23.

[24] Chotai S, Sivaganesan A, Parker SL, Wick J, Stonko DP, McGirt MJ, et al. 106 Effect of Complications Within 90 Days on Cost-Utility Following Elective Surgery for Degenerative Lumbar Spine Disease. Neurosurgery. 2016; 63 Suppl 1:145.

[25] Shimizu T, Fujibayashi S, Takemoto M, Otsuki B, Kimura H, Ota $\mathrm{M}$, et al. A multi-center study of reoperations within 30 days of spine surgery. European spine journal: official publication of the European Spine Society, the European Spinal Deformity Society, and the European Section of the Cervical Spine Research Society. 2016; 25 (3):828-35.

[26] Ojo OA, Owolabi BS, Oseni AW, Kanu OO, Bankole OB. Surgical site infection in posterior spine surgery. Nigerian journal of clinical practice. 2016; 19 (6):821-6. 